\title{
Analysis of the direct effects of prostaglandins on human sperm function
}

\author{
R. J. Aitken and R. W. Kelly \\ MRC Reproductive Biology Unit, 37 Chalmers Street, Edinburgh EH3 9EW, U.K.
}

\begin{abstract}
Summary. Time-exposure photomicrography and interspecies in-vitro fertilization procedures have been used to examine the influence of prostaglandins on human sperm function. An analysis of variance indicated that the presence of PGs in the incubation media was associated with a significant increase in sperm velocity and the frequency of sperm head rotation, although there were no differences between individual PGs in the degree of stimulation observed. Changes in the penetrating ability of human spermatozoa were detected after exposure to PGs, particularly PGE-1 and PGE-2. PGE-2 induced a sustained increase in penetration rates at all doses of $>8.4 \mu \mathrm{g} / \mathrm{ml}$, while exposure to PGE-1 gave a bell-shaped dose-response curve which exhibited a peak between 8.4 and $33.3 \mu \mathrm{g} / \mathrm{ml}$ and progressively fell to reach control levels at the maximum concentration tested of $270 \mu \mathrm{g} / \mathrm{ml}$. A combination of PGE-2 and PGE-1 produced a dose-response curve similar to that for PGE-1 alone, while exposure to PGF-2 $\alpha$ was without effect. Seminal extracts containing predominantly 19-hydroxy PGE-1, or equal amounts of 19-hydroxy PGE-1 + 2 induced a slight, but significant, rise in penetration rates while a combination of PGs representing the major components of human seminal plasma was without significant effect. We conclude that certain prostaglandins may have a direct action on the functional competence of human spermatozoa.
\end{abstract}

\section{Introduction}

The entire field of prostaglandin (PG) research was originally stimulated by the striking pharmacological properties of human seminal plasma, the PG content of which may exceed 1 $\mathrm{mg} / \mathrm{ml}$, largely due to the presence of considerable quantities of PGE (Samuelsson, 1963) and 19hydroxy PGE (Taylor \& Kelly, 1974; Jonsson, Middleditch \& Desiderio, 1975; Templeton, Cooper \& Kelly, 1978; Gerozissis \& Dray, 1981). Although several reports have appeared in the literature linking low levels of PGE in human semen with unexplained infertility (Hawkins, 1968; Bydgeman, Fredricsson, Svanborg \& Samuelsson, 1970; Collier, Flower \& Stanton, 1975), the wide range of $P G$ concentrations recorded in the semen of fertile men as well as technical problems associated with semen storage and the accurate measurement of PG levels (Templeton et al., 1978) render such correlations questionable. The results of the few in-vitro experiments conducted on the influence of prostaglandins on human sperm function have also been inconclusive, claiming to provide evidence of an inhibition (Cohen, Colin, Golimbu \& Hotchkiss, 1977; Read \& Schnieden, 1978) and a stimulation (Schlegel, Rotermund, Farber \& Nieschlag, 1981) of sperm motility. In the light of this uncertainty we have re-examined the possible significance of prostaglandins in the regulation of human sperm function using objective, time-exposure photomicrography and in-vitro fertilization techniques to monitor changes in the movement characteristics and penetrating ability of the spermatozoa. 


\section{Materials and Methods}

Prostaglandins. Prostaglandins E-1, E-2 and F-2 $\alpha$ were purchased from Sigma Chemical Co., St Louis, MO, U.S.A.).

A 19-hydroxy PGE-1 + 2 extract was prepared from a $160 \mathrm{ml}$ pool of human seminal plasma from $53 \mathrm{men}$, which had been stored in acetone $(400 \mathrm{ml})$ at $-20^{\circ} \mathrm{C}$. The acetone suspension was centrifuged at $1000 \mathrm{~g}$ for $10 \mathrm{~min}$ after which the pellet was washed with a further $200 \mathrm{ml}$ acetone; the supernatants were subsequently combined and evaporated on a rotary evaporator to a volume of $150 \mathrm{ml}$. Citric acid was added to the residue to give a $\mathrm{pH}$ of 3 and the PGs were extracted with 2 $\times 400 \mathrm{ml}$ ether-ethyl acetate $(1: 1 \mathrm{v} / \mathrm{v})$. The ethereal extracts were combined, dried $\left(\mathrm{Mg}_{2} \mathrm{SO}_{4}\right)$ and evaporated to dryness to give a residue of $175 \mathrm{mg}$. The residue was chromatographed on Sephadex LH 20 using a $150 \times 0.5 \mathrm{~cm}$ column and eluting with chloroform-ethyl acetate-acetic acid $(50: 50: 1$, by vol. $) ; 4 \mathrm{ml}$ fractions were collected and assayed by gas chromatography. Fractions $76-$ 99 containing 19-hydroxy PGE-1 and 19-hydroxy PGE-2 were combined to give a total of $5.4 \mathrm{mg}$ extract. Gas chromatography indicated that this material was $>90 \%$ pure, containing $<2 \%$ PGE and consisting of equal amounts of 19-hydroxy PGE-1 and 19-hydroxy PGE-2.

A preparation enriched in 19-hydroxy PGE-1, was prepared from 20 seminal plasma samples obtained from 3 stump-tailed macaques (Macaca arctoides) using identical procedures. Gas chromatography indicated that this preparation comprised $81 \cdot 2 \% 19$-hydroxy PGE-1 and $14.4 \%$ 19-hydroxy PGE-2.

The PG preparations were made up in ethanol, transferred to clean flat-bottomed tubes and dried under negative pressure before the addition of Medium BWW (Biggers, Whitten \& Whittingham, 1971).

Sperm movement characteristics. These were measured using time-exposure photomicrography with the principles laid down by Overstreet, Katz, Hanson \& Fonseca (1979) and the detailed methodology of Aitken et al. (1982). The measurements were made at $37^{\circ} \mathrm{C}$ under dark-field illumination and an exposure time of $1 \mathrm{sec}$. From the photographs, calculations were made of the forward velocity of the cells, the amplitude of lateral head displacement and the frequency of sperm head rotation. The patterns of sperm movement were also classified as rolling, yawing (Overstreet et al., 1979) or without significant lateral displacement. To assess each criterion of movement 20 tracks were used and the measurements were made on both the total motile sperm population and those spermatozoa exhibiting a progressive velocity of $>25 \mu \mathrm{m} / \mathrm{sec}$ (Overstreet et al., 1979).

The movement characteristics of the spermatozoa were measured after incubation for $3 \mathrm{~h}$ at the same time as the oocytes were introduced into the sperm suspensions. The changes in sperm motility were evaluated using PGE-1, PGE-2, 19-hydroxy PGE-1 and PGF-2 $\alpha$ at a dose of 67.5 $\mu \mathrm{g} / \mathrm{ml}$, performing 4 independent experiments for each compound.

In-vitro penetration. Twenty-one semen samples obtained from 2 donors of proven fertility were produced by masturbation and collected into sterile plastic containers. Within 5 min the samples were placed in a $37^{\circ} \mathrm{C}$ incubator and left for $30 \mathrm{~min}$ to liquefy. The penetrating ability of the spermatozoa was assessed by the zona-free hamster oocyte penetration assay (Yanagimachi, Yanagimachi \& Rogers, 1976), using a calcium-containing medium based on the Krebs-Ringerbicarbonate buffer described by Biggers et al. (1971) as modified by Aitken, Wang, Lui, Best \& Richardson (1983). The protocol was exactly as described by Aitken et al. (1983), incorporating a 3-h preincubation period to effect capacitation, then introduction of zona-free oocytes and incubation for a further $3 \mathrm{~h}$. The oocytes were subsequently removed from the sperm suspensions, washed, and scored for the presence of penetrated spermatozoa by phase-contrast microscopy. The outcome of the in-vitro test was assessed on at least 20 oocytes in terms of the percentage of oocytes penetrated and the mean number of penetrated spermatozoa per egg. The assay was carried out using a total sperm concentration of $10 \times 10^{6}$ spermatozoa $/ \mathrm{ml}$ and the results were subsequently adjusted for a standard concentration of $5 \times 10^{6}$ motile spermatozoa $/ \mathrm{ml}$. This correction was based 
on Poisson distribution theory (Aitken \& Elton, 1984) according to the following formula: $p_{2}=1$ $\exp \left(-r m_{1}\right)$ where $p_{2}=$ the corrected penetration rate for a motile sperm concentration of $5 \times$ $10^{6} / \mathrm{ml}, r=$ the ratio of the theoretical concentration of motile spermatozoa (i.e. 5) to the actual concentration of motile spermatozoa, and $m_{1}=$ mean number of spermatozoa penetrating each oocyte in the experiment. Three or 4 independent dose-response experiments were carried out for each of the prostaglandins, covering concentrations ranging from 4.2 to $270 \mu \mathrm{g} / \mathrm{ml}$.

Statistical analysis. The statistical significance of the results was assessed by analysis of variance (Winer, 1971). For the in-vitro experiments, differences between the controls and various prostaglandin treatments were evaluated by using Dunnetts procedure (Winer, 1971).

\section{Results}

Movement characteristics of spermatozoa

Analysis of variance indicated a significant increase in the total mean velocity of the spermatozoa after the addition of PG $(P<0.01)$ although no differences could be detected between the individual $P G$ species in the degree of stimulation observed (Table 1). Similarly, when the analysis was confined to the progressive population of spermatozoa moving at $>25 \mu \mathrm{m} / \mathrm{sec}$, a significant increase in forward velocity was noted $(P<0.01)$ without any apparent difference in the effectiveness of the individual PG species (Table 1).

Table 1. Influence of prostaglandins (PG) on the forward velocity of human spermatozoa

\begin{tabular}{|c|c|c|c|c|}
\hline \multirow[b]{3}{*}{ PG } & \multicolumn{4}{|c|}{ Mean \pm s.e.m. velocity $(\mu \mathrm{m} / \mathrm{sec})$} \\
\hline & \multicolumn{2}{|c|}{ Total spermatozoa } & \multicolumn{2}{|c|}{ Progressive spermatozoa } \\
\hline & Control & $\mathrm{PG}^{*}$ & Control & $\mathrm{PG}^{*}$ \\
\hline $\begin{array}{l}\text { PGE-1 } \\
\text { 19-hydroxy PGE-1 } \\
\text { PGE-2 } \\
\text { PGF-2 } \alpha\end{array}$ & $\begin{array}{l}42 \cdot 4 \pm 3 \cdot 3 \\
42 \cdot 5 \pm 3 \cdot 8 \\
46 \cdot 2 \pm 2 \cdot 6 \\
44 \cdot 4 \pm 2 \cdot 7\end{array}$ & $\begin{array}{l}52 \cdot 3 \pm 4 \cdot 6 \\
50 \cdot 4 \pm 3 \cdot 6 \\
48 \cdot 1 \pm 6 \cdot 5 \\
49 \cdot 8 \pm 1 \cdot 9\end{array}$ & $\begin{array}{l}43 \cdot 2 \pm 3 \cdot 4 \\
42 \cdot 9 \pm 3 \cdot 4 \\
48 \cdot 1 \pm 2 \cdot 4 \\
44 \cdot 7 \pm 2 \cdot 4\end{array}$ & $\begin{array}{l}52 \cdot 8 \pm 4 \cdot 3 \\
50 \cdot 6 \pm 3 \cdot 5 \\
48 \cdot 5 \pm 6 \cdot 1 \\
49 \cdot 8 \pm 1 \cdot 9\end{array}$ \\
\hline
\end{tabular}

$\dagger>25 \mu \mathrm{m} / \mathrm{sec}$.

* Difference between control and prostaglandin treatment, $P<0.01$.

The PG-induced stimulation of sperm velocity was associated with an increase in the frequency of sperm head rotation in the total $(P<0.05)$ and progressively motile $(P<0.05)$ sperm populations. Again, however the analysis of variance did not reveal any differences between the various PGs in their effectiveness at stimulating this aspect of sperm behaviour (Table 2).

The amplitude of lateral head displacement showed a tendency to increase after the addition of PGF-2 $\alpha$ and 19-hydroxy PGE-1 although this trend did not reach statistical significance regardless of whether the results were expressed as a mean distance of displacement (Table 2) or classified as more or less than $10 \mu \mathrm{m}$ (data not shown).

The predominant motility pattern exhibited by the spermatozoa was a 'rolling' motion, which accounted for more than $80 \%$ of the cells examined in all the preparations analysed. However, no significant changes were detected in the proportion of 'rolling' spermatozoa after addition of PGs (Table 2). Similarly, the proportion of spermatozoa exhibiting a 'yawing' or 'minimal displacement' motion was not significantly influenced by the addition of PGs (data not shown). 
Table 2. Influence of prostaglandins (PG) on the frequency of sperm head rotation, amplitude of lateral head displacement and the proportion of rolling spermatozoa (mean \pm s.e.m.)

\begin{tabular}{|c|c|c|c|c|c|}
\hline \multirow[b]{2}{*}{ Movement characteristic } & \multirow[b]{2}{*}{ PG } & \multicolumn{2}{|c|}{ Total population } & \multicolumn{2}{|c|}{ Progressive population $\dagger$} \\
\hline & & Control & PG & Control & PG \\
\hline $\begin{array}{l}\text { Frequency of sperm head } \\
\text { rotation (rotations } / \mathrm{sec})^{*}\end{array}$ & $\begin{array}{l}\text { PGE-1 } \\
\text { 19-Hydroxy PGE-1 } \\
\text { PGE-2 } \\
\text { PGF-2 } \alpha\end{array}$ & $\begin{array}{r}10 \cdot 3 \pm 1 \cdot 2 \\
9 \cdot 9 \pm 0 \cdot 9 \\
10 \cdot 3 \pm 0 \cdot 6 \\
8 \cdot 7 \pm 0.6\end{array}$ & $\begin{array}{l}11 \cdot 3 \pm 1 \cdot 1 \\
11 \cdot 1 \pm 0 \cdot 7 \\
10 \cdot 9 \pm 1 \cdot 5 \\
10 \cdot 4 \pm 0 \cdot 4\end{array}$ & $\begin{array}{r}10.5 \pm 1.2 \\
10.0 \pm 0.7 \\
10.8 \pm 0.6 \\
8.8 \pm 0.5\end{array}$ & $\begin{array}{l}11 \cdot 4 \pm 1 \cdot 1 \\
11 \cdot 1 \pm 0 \cdot 6 \\
11 \cdot 0 \pm 1 \cdot 4 \\
10 \cdot 4 \pm 0.4\end{array}$ \\
\hline $\begin{array}{l}\text { Amplitude of lateral sperm } \\
\text { head displacement }(\mu \mathrm{m})\end{array}$ & $\begin{array}{l}\text { PGE-1 } \\
\text { 19-hydroxy PGE-1 } \\
\text { PGE-2 } \\
\text { PGF-2 } \alpha\end{array}$ & $\begin{array}{l}9.1 \pm 0.4 \\
8.5 \pm 0.4 \\
9 \cdot 6 \pm 0.2 \\
7.9 \pm 0.7\end{array}$ & $\begin{array}{l}9 \cdot 1 \pm 0 \cdot 5 \\
9 \cdot 2 \pm 0 \cdot 2 \\
9 \cdot 5 \pm 0 \cdot 2 \\
9 \cdot 3 \pm 0.4\end{array}$ & $\begin{array}{l}9.2 \pm 0.3 \\
8.7 \pm 0.4 \\
9.4 \pm 0.2 \\
7.9 \pm 0.7\end{array}$ & $\begin{array}{l}9 \cdot 1 \pm 0 \cdot 5 \\
9 \cdot 2 \pm 0 \cdot 2 \\
9 \cdot 4 \pm 0 \cdot 2 \\
9 \cdot 3 \pm 0 \cdot 4\end{array}$ \\
\hline Rolling (\%) & $\begin{array}{l}\text { PGE-1 } \\
\text { 19-hydroxy PGE-1 } \\
\text { PGE-2 } \\
\text { PGF-2 } \alpha\end{array}$ & $\begin{array}{l}93 \cdot 7 \pm 3 \cdot 7 \\
88 \cdot 7 \pm 4 \cdot 2 \\
91 \cdot 8 \pm 4 \cdot 7 \\
88 \cdot 7 \pm 4 \cdot 2\end{array}$ & $\begin{array}{l}93 \cdot 7 \pm 3 \cdot 1 \\
95 \cdot 0 \pm 2 \cdot 0 \\
98 \cdot 7 \pm 1 \cdot 2 \\
93 \cdot 7 \pm 4 \cdot 7\end{array}$ & $\begin{array}{l}93 \cdot 2 \pm 3 \cdot 9 \\
88 \cdot 7 \pm 4 \cdot 2 \\
91 \cdot 1 \pm 5 \cdot 2 \\
88 \cdot 7 \pm 4 \cdot 2\end{array}$ & $\begin{array}{l}93 \cdot 2 \pm 3 \cdot 6 \\
95 \cdot 0 \pm 2 \cdot 0 \\
98 \cdot 7 \pm 1 \cdot 2 \\
93.7 \pm 4 \cdot 7\end{array}$ \\
\hline
\end{tabular}

$\dagger>25 \mu \mathrm{m} / \mathrm{sec}$.

* Differences between control and prostaglandin treatment, $P<0.05$.

Finally, none of the PGs evaluated induced any changes in the absolute number of motile spermatozoa present in the incubation media. Small differences in the proportion of motile cells $(50-80 \%)$ were observed between the 16 ejaculates used in this section of the study, however, and for this reason the results described in the following section have been adjusted for a fixed concentration of $5 \times 10^{6}$ motile cells $/ \mathrm{ml}$ using Poisson distribution theory.

\section{In-vitro penetration}

A dose-response analysis was carried out for each $P G$ and the results are summarized in Textfig. 1. In the presence of PGE-2 a significant $(P<0.005)$ stimulation of hamster oocyte penetration was observed at all dose levels studied $(4 \cdot 2-270 \mu \mathrm{g} / \mathrm{ml})$. The addition of PGE-1 induced a similar significant increase in penetration rates $(P<0.005)$ which reached a peak between 8.4 and 33.6 $\mu \mathrm{g} / \mathrm{ml}$ but thereafter declined, so that at the highest concentration tested $(270 \mu \mathrm{g} / \mathrm{ml})$ the results were not significantly different from the controls. When a $1: 1$ combination of PGE-1 and PGE-2 was used, the PGE-1 pattern of response predominated, producing an increase in penetration rates which reached a peak between 16.8 and $33.6 \mu \mathrm{g} / \mathrm{ml}$ but thereafter declined to reach control levels at $270 \mu \mathrm{g} / \mathrm{ml}$. In contrast to the PGEs, PGF- $2 \alpha$ had no significant effect on the penetrating ability of human spermatozoa.

The 19-hydroxy PGs exerted a weak stimulatory action on penetration rates. Addition of the preparation containing predominantly 19-hydroxy PGE-1 produced a small rise in the mean percentage of hamster oocytes penetrated at all dose levels tested, but this increase only reached statistical significance at a concentration of $135 \mu \mathrm{g} / \mathrm{ml}(P<0.05)$. The 19-hydroxy PGE-1 +2 , preparation was a more effective stimulator of human sperm function than the 19-hydroxy PGE-1 material, producing a significant increase in penetration rates at all doses above $8.4 \mu \mathrm{g} / \mathrm{ml}(P<$ $0.05)$ and reaching a peak at $270 \mu \mathrm{g} / \mathrm{ml}(P<0.01)$.

In all of the above experiments the PGs were present throughout the in-vitro penetration period. To rule out an effect on the oocytes, a subsequent experiment was performed in which the PGs were incorporated into the medium during the preincubation phase only. The anticipated 


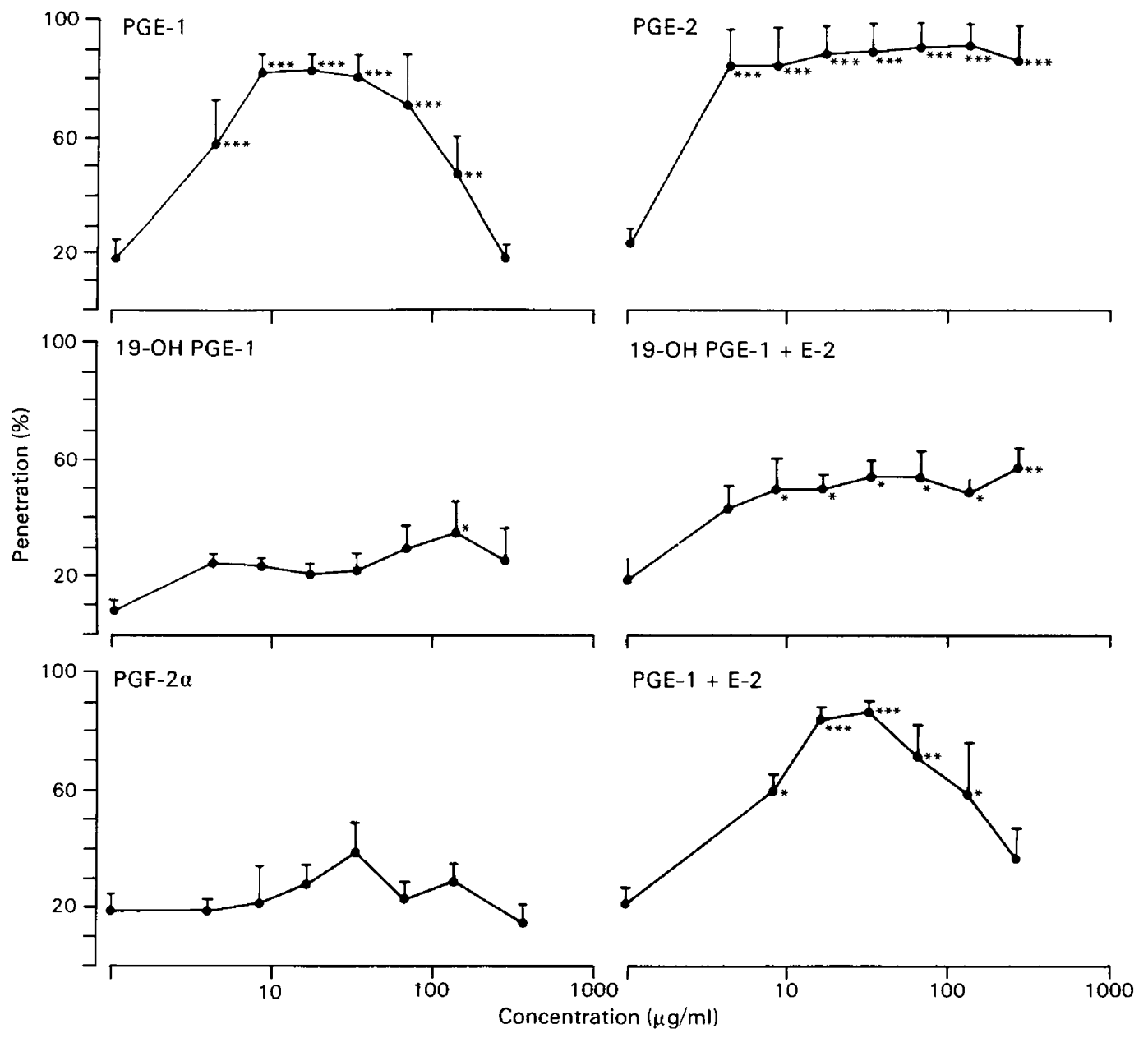

Text-fig. 1. Influence of prostaglandins on the ability of human spermatozoa to penetrate zonafree hamster oocytes: all results corrected to a motile sperm concentration of $5 \times 10^{6} / \mathrm{ml}$. The dose-response curves were constructed from data obtained from 3 separate experiments for all PGs except for 19-hydroxy PGE-1, for which $n=4$. Points and error bars indicate mean and standard error for the results obtained for each dose. ${ }^{*} P<0.05,{ }^{* *} P<0.01,{ }^{* * *} P<0.005$, compared with control (analysis of variance data according to Dunnetts procedure; Winer, 1971).

increase in penetration rates was again observed with the E-series prostaglandins to give results of 77.7 and $95.4 \%$ with PGE-1 and PGE-2, respectively compared with values of $38.5,38.4$ and $43.7 \%$ with the control, 19-hydroxy PGE-1 and PGF2 $\alpha$ incubations, respectively.

In a final experiment a combination of PGs equivalent to that observed in human seminal plasma was examined for its effect on the penetrating ability of human spermatozoa. After exposure to a mixture containing 19-hydroxy PGE-1 $(135 \mu \mathrm{g} / \mathrm{ml}), 19$-hydroxy PGE-2 $(135 \mu \mathrm{g} / \mathrm{ml})$, PGE-1, (35 $\mu \mathrm{g} / \mathrm{ml})$ and PGE-2 $(35 \mu \mathrm{g} / \mathrm{ml})$, the penetration rates exhibited a statistically insignificant fall from a control value of 50.1 to $34.4 \%$, equivalent to 39.3 and $28.1 \%$ respectively, when the results were corrected for a fixed concentration of $5 \times 10^{6}$ motile spermatozoa $/ \mathrm{ml}$. 


\section{Discussion}

This study has demonstrated, for the first time, that prostaglandins, at concentrations equivalent to those found in human seminal plasma, can exert direct effects on human sperm function. These effects were observed in two directions, firstly a stimulation of both the linear velocity of sperm progression and the frequency of sperm head rotation, and secondly, a paradoxical stimulation of the ovum-penetrating ability of the spermatozoa.

The stimulation of sperm motility is consistent with the results of in-vitro experiments indicating a reduction in sperm motility following inactivation of seminal prostaglandins with prostaglandin-15-hydroxy dehydrogenase in the rabbit (Schlegel, Fischer, Beier \& Schneider, 1983) and man (Schlegel et al., 1981). The concentrations of PGE-1, PGE-2 and 19-hydroxy PGE-1 used in this study were within the normal range of values recorded for human seminal plasma (Templeton et al., 1978), suggesting a possible physiological role for these seminal prostaglandins in the regulation of human sperm motility. Failure to observe changes in sperm motility or metabolism in response to prostaglandin treatment in previous studies may have been due to the use of subjective ranking systems to evaluate sperm motility (Read \& Schnieden, 1978) or of calcium-free incubation media (Eliasson, Murdoch \& White, 1968; Garbers, Lust, First \& Lardy, 1971).

A previous analysis of the relationship between sperm motility and the PGF- $2 \alpha$ content of human seminal plasma revealed the presence of a significant negative correlation between these factors (Schlegel et al., 1981). The implication of these findings, that excessively high levels of PGF- $2 \alpha$ might exert a direct negative effect on sperm motility, was supported by the results of an in-vitro study (Cohen et al., 1977) in which a significant suppression of sperm motility was observed in the presence of $250 \mu \mathrm{g}$ PGF- $2 \alpha / \mathrm{ml}$. We examined the direct effects of PGF- $2 \alpha$ on sperm motility using a PG concentration which was intermediate between the excessive dose employed by Cohen et al. (1977) and the elevated levels reported in patients with depressed sperm motility (Schlegel $e t$ al., 1981). Since a stimulation of sperm velocity and frequency of sperm head rotation was observed in this analysis, without any change in the concentration of motile cells, the elevated PGF- $2 \alpha$ levels recorded by Schlegel et al. (1981) could not have been directly responsible for the suppression of sperm motility.

The mechanism by which seminal prostaglandins stimulate sperm motility may involve an enhancement of adenylate cyclase activity and a subsequent rise in cAMP levels. Prostaglandins, particularly PGE-1, are known to be potent stimulators of adenylate cyclase in a number of cell systems (Marsh \& LeMaire, 1974) and a positive relationship between intracellular cAMP levels and sperm motility has been repeatedly demonstrated (Tash \& Means, 1983). Although previous studies on bovine and primate spermatozoa have failed to observe a stimulation of cAMP production after prostaglandin treatment (Garbers et al., 1971; Casillas \& Hoskins, 1971), it may be significant that these experiments were carried out in calcium-free media. The adenylate cyclase of human spermatozoa is known to be influenced by the availability of free $\mathrm{Ca}^{2+}$ (Hyne \& Lopata, 1982) while the biological activity of the prostaglandins may well depend upon their ability to regulate the uptake (Kirtland \& Baum, 1972) or binding (Horrobin, 1977) of calcium by cells, as discussed below.

This study has also revealed a direct, paradoxical effect of certain prostaglandins, particularly PGE-1 and PGE-2, on the fertilizing ability of human spermatozoa. This could not have been the consequence of a non-specific perturbation of the plasma membrane because PGF- $2 \alpha$ was without effect. Similarly, the increase in penetration rates was not a consequence of the enhancement of sperm motility because PGF- $2 \alpha$, which was as competent as the other prostaglandins in stimulating sperm velocity, did not exert a significant influence on the outcome of the in-vitro penetration assay. In contrast, the addition of PGE-2 produced a significant and sustained increase in penetration rates which reached maximal levels at doses above $8.4 \mu \mathrm{g} / \mathrm{ml}$. However, the response to PGE-1 was quite different, involving a marked stimulation of oocyte penetration at doses upto 33.7 
$\mu \mathrm{g} / \mathrm{ml}$ but thereafter an equally marked inhibition, so that penetration rates returned to control levels at the maximum dose of $270 \mu \mathrm{g} / \mathrm{ml}$. This 'bell-shaped' dose-response curve is typical of the response to prostaglandin stimulation in many biological systems, including human red cell deformability, the secretion of prolactin from cultured rat pituitary cells or the refractory period of capillary muscle (Horrobin, 1977). Horrobin (1977) has suggested that the biological effects of prostaglandins may depend upon their ability to regulate the availability of $\mathrm{Ca}^{2+}$ binding sites within the cell. According to this model, the interaction between prostaglandins and PG receptors induces the activation of adjacent $\mathrm{Ca}^{2+}$ binding sites, the occupation of which leads to the subsequent expression of biological activity. A bell-shaped dose-response curve is produced because at higher $\mathrm{PG}$ concentrations the $\mathrm{Ca}^{2+}$ binding site itself becomes occupied or inactivated and the biological response is correspondingly diminished. Since $\mathrm{Ca}^{2+}$ entry into the sperm cell is known to be a critical event during capacitation and the subsequent acrosome reaction (Triana, Babcock, Lorton, First \& Lardy, 1980; Yanagimachi, 1981), a prostaglandin involvement in the regulation of $\mathrm{Ca}^{2+}$ binding to components of the spermatozoon is an attractive concept. An alternative hypothesis may be that prostaglandins stimulate the fertilizing ability of human spermatozoa by acting as ionophores and directly facilitating the transport of $\mathrm{Ca}^{2+}$ across the sperm plasma membrane (Kirtland \& Baum, 1972). Recognized calcium ionophores such as A23187 have been shown to have a profound stimulatory effect on the ability of human spermatozoa to undergo the acrosome reaction and penetrate zona-free hamster oocytes (Russell, Peterson \& Freund, 1979; R. J. Aitken, unpublished observations).

While a role for seminal prostaglandins in the maintenance of sperm motility would seem logical, the biological meaning of the stimulatory effects on the fertilizing ability of human spermatozoa is less clear. The presence of decapacitating factors in human seminal plasma (Kanwar, Yanagimachi \& Lopata, 1979) would negate any stimulatory action of seminal prostaglandins in this regard. However, once the spermatozoa have escaped from seminal plasma the presence of prostaglandins in the female reproductive tract or the generation of prostaglandins by the spermatozoa themselves might have a marked effect on their fertilizing ability. The available evidence suggests that, although human spermatozoa are unable to manufacture prostaglandins de novo from labelled arachidonic acid (Schlegel et al., 1981), there are numerous sites in the female reproductive tract where exogenous PGs might influence sperm function (Charbonnel, Kremer, Gerozissis \& Dray, 1982). Elucidation of the significance of prostaglandins as biological inducers of sperm capacitation must await the outcome of studies on the concentrations of these compounds in the female reproductive tract at mid-cycle. In the meantime it should be emphasized that these results have important therapeutic implications for the treatment of male infertility. In particular, consideration might now be given to the possibility of using prostaglandins of the $\mathrm{E}$ series to stimulate artificially the fertilizing ability of human spermatozoa in the clinical application of the in-vitro fertilization/embryo transfer procedure.

We thank Ms Fiona Best and Mr D. W. Richardson for their invaluable assistance in the realization of this project.

\section{References}

Aitken, R.J. \& Elton, R.A. (1984) Significance of Poisson distribution theory in analysing the interaction between human spermatozoa and zona-free hamster oocytes. J. Reprod. Fert. 72, 311-321.

Aitken, R.J., Best, F.S.M., Richardson, D.W., Djahanbakhch, O., Templeton, A., \& Lees, M.M. (1982) An analysis of semen quality and sperm function in cases of oligozoospermia. Fert. Steril. 38, 705-711.
Aitken, R.J., Wang, Y.-F., Lui, R., Best, F.S.M. \& Richardson, D.W. (1983) The influence of medium composition, osmolarity and albumin content on the acrosome reaction and fertilizing capacity of human spermatozoa: development of an improved zona free hamster egg penetration test. Int. J. Androl. 6, 180 193.

Biggers, J.D., Whitten, W.K. \& Whittingham, D.G. 
(1971) The culture of mouse embryos in vitro. In Methods in Mammalian Embryology, pp. 56-116. Ed.

J. C. Daniel, Jr, Freeman, San Francisco.

Bygdeman, M., Fredricsson, B., Svanborg, K. \& Samuelsson, B. (1970) The relation between fertility and prostaglandin content of seminal fluid in man. Fert. Steril. 21, 622-629.

Casillas, E.R. \& Hoskins, D.D. (1971) Adenyl cyclase activity and cyclic $3^{1}, 5^{1}$-AMP content of ejaculated monkey spermatozoa. Archs Biochem. Biophys. 147, $148-155$.

Charbonnel, B., Kremer, M., Gerozissis, K. \& Dray, F. (1982) Human cervical mucus contains large amounts of prostaglandins. Fert. Steril 38, 109-111.

Cohen, M.S., Colin, M.J., Golimbu, M. \& Hotchkiss, R.S. (1977) The effects of prostaglandins on sperm motility. Fert. Steril. 28, 78-85.

Collier, J.G., Flower, R.J. \& Stanton, S.L. (1975) Seminal prostaglandins in infertile men. Fert. Steril. 26, 868873.

Eliasson, R., Murdoch, R.N. \& White, I.G. (1968) The metabolism of human spermatozoa in the presence of prostaglandin E. Acta physiol. scand. 73, 379-382.

Garbers, D.L., Lust, W.D., First, N.L. \& Lardy, H.A. (1971) Effects of phosphodiesterase inhibitors and cyclic nucleotides on sperm respiration and motility. Biochemistry, N.Y. 10, 1825-1831.

Gerozissis, K. \& Dray, F. (1981) Radioimmunoassay of prostaglandins in the semen of fertile men. J. Reprod. Fert. 61, 487-490.

Hawkins, D.F. (1968) Relevance of prostaglandins to problems of human subfertility. In Prostaglandin Symposium of the Worcester Foundation, pp. 1-10. Eds P. W. Ramwell \& J. E. Shaw. Interscience, New York.

Horrobin, D.F. (1977) Interactions between prostaglandins and calcium: the importance of bell-shaped dose response curves. Prostaglandins 14, 667-677.

Hyne, R.V. \& Lopata, A. (1982) Calcium and adenosine affect human sperm adenylate cyclase activity. Gamete Res. 6, 81-89.

Jonsson, H.T., Middleditch, B.S. \& Desiderio, D.M. (1975) Prostaglandin in human seminal fluid: two novel compounds. Science, N.Y. 187, 1093-1094.

Kanwar, K.C., Yanagimachi, R. \& Lopata, A. (1979) Effects of human seminal plasma on fertilizing capacity of human spermatozoa. Fert. Steril. 31, 321327.

Kirtland, S.J. \& Baum, H. (1972) Prostaglandin $\mathrm{E}_{1}$ may act as a calcium ionophore. Nature, Lond. 236, 47-49.

Marsh, J.M. \& LeMaire, W.J. (1974) Cyclic AMP accumulation and steroidogenesis in the human corpus luteum: effect of gonadotropins and prostaglandins. J. clin. Endocr. Metab. 38, 99-106.

Overstreet, J.W., Katz, D.F., Hanson, F.W. \& Tonseca, J.R. (1979) A simple inexpensive method for objective assessment of human sperm movement characteristics. Fert. Steril. 31, 162-172.

Read, M.D. \& Schnieden, H. (1978) Effect of two methylxanthine derivatives and four prostaglandins on the motility of spermatozoa from volunteers and oligozoospermic patients. Int. J. Androl. 1, 220-224.

Russell, L., Peterson, R.N. \& Freund, M. (1979) Morphologic characteristics of the chemically induced acrosome reaction in human spermatozoa. Fert. Steril. 32, 87-92.

Samuelsson, B. (1963) Isolation and identification of prostaglandins from human seminal plasma. $J$. biol. Chem. 238, 3229-3234.

Schlegel, W., Rotermund, S., Farber, G. \& Nieschlag, E. (1981) The influence of prostaglandins on sperm motility. Prostaglandins 21, 87-99.

Schlegel, W., Fischer, B., Beier, H.M. \& Schneider, H.P.G. (1983) Effects on fertilization of rabbits of insemination with ejaculates treated with PG-dehydrogenase and antisera to PGE-2 and PGF-2 $\alpha . J$. Reprod. Fert. 68, 45-50.

Tash, J.S. \& Means, A.R. (1983) Cyclic adenosine 3'5' monophosphate, calcium and protein phosphorylation in flagellar motility. Biol. Reprod. 28, 75-104.

Taylor, P.L. \& Kelly, R.W. (1974) 19-Hydroxylated E prostaglandins as the major prostaglandins of human semen. Nature, Lond. 250, 665-667.

Templeton, A.A., Cooper, I. \& Kelly, R.W. (1978) Prostaglandin concentrations in the semen of fertile men. J. Reprod. Fert. 52, 147-150.

Triana, L.R., Babcock, D.F., Lorton, S.P., First, N.L. \& Lardy, H.A. (1980) Release of acrosomal hyaluronidase follows increased membrane permeability to calcium in the presumptive capacitation sequence for spermatozoa of the bovine and other mammalian species. Biol. Reprod. 23, 47-59.

Winer, B.J. (1971) Statistical Principles in Experimental Design, 2nd edn. McGraw-Hill, New York.

Yanagimachi, R. (1981) Mechanisms of fertilization in mammals. In Fertilization and Embryonic Development In Vitro, pp. 81-182. Eds L. Mastroianni \& J. D. Biggers. Plenum, New York.

Yanagimachi, R., Yanagimachi, H. \& Rogers, B.J. (1976) The use of zona free animal ova as a test system for the assessment of fertilizing capacity of human spermatozoa. Biol. Reprod. 15, 471-476.

Received 2 April 1984 